\title{
Distribution Patterns (7B Rule) and Characteristics of Large Congenital Melanocytic Nevi: A Retrospective Cohort Study in China
}

\begin{abstract}
Huijing Wang ${ }^{1 \dagger}$, Wei Wang ${ }^{1 \dagger}$, Jun $\mathrm{Lu}^{2 \dagger}$, Yihui Gu ${ }^{1}$, Xiwei Cui ${ }^{1}$, Chengjiang Wei ${ }^{1}$, Jieyi Ren ${ }^{1}$, Bin $\mathrm{Gu}^{1}$, Zhichao Wang ${ }^{1 *}$ and Qingfeng $\mathrm{Li}^{1 *}$

'Department of Plastic and Reconstructive Surgery, Shanghai Ninth People's Hospital, Shanghai Jiao Tong University School of Medicine, Shanghai, China, ${ }^{2}$ Division of Epidemiology and Biostatistics, School of Public Health, University of Illinois at Chicago, Chicago, IL, United States
\end{abstract}

OPEN ACCESS

Edited by: Mitchell Stark,

The University of

Queensland, Australia

Reviewed by:

Unni Krishna SRL Samavedam, University of Cincinnati, United States

Elisabetta Palazzo,

University of Modena and Reggio Emilia, Italy

${ }^{*}$ Correspondence:

Zhichao Wang

shmuwzc@163.com

Qingfeng Li

dr.liqingfeng@yahoo.com

tThese authors have contributed equally to this work and share first authorship

\footnotetext{
Specialty section:

This article was submitted to Dermatology,

a section of the journal

Frontiers in Medicine
}

Received: 04 December 2020 Accepted: 01 February 2021

Published: 19 February 2021

Citation: Wang H, Wang W, Lu J, Gu Y, Cui X, Wei C, Ren J, Gu B, Wang Z and Li Q (2021) Distribution Patterns (7B Rule) and Characteristics of Large

Congenital Melanocytic Nevi: A Retrospective Cohort Study in China. Front. Med. 8:637857. doi: 10.3389/fmed.2021.637857
Large congenital melanocytic nevus has a high risk of malignancy. However, few studies have summarized its characteristics, treatments, outcomes and malignancy incidence in Chinese patients. This paper reviews a retrospective cohort study evaluating 1,171 patients from Shanghai Ninth People's Hospital between 1 January 1989 and 31 August 2019 using electronic medical records and phone calls to collect clinical and pathological data in which 133 patients were diagnosed with a large congenital melanocytic nevus. Three patients relapsed, and none developed melanoma among the qualified patients. Besides, a new "7B" rule for distribution patterns of large congenital melanocytic nevi was proposed, including bonce, bolero, back, bathing trunk, breast/belly, body extremity, and body. The most common distribution pattern of large congenital melanocytic nevi was bonce, and all blue nevi distributed as bonce. Statistical analysis showed a significant difference $(P=0.0249)$ in the "7B" patterns between the melanocytic nevus and the neuronevus. In conclusion, the malignancy rate of large congenital melanocytic nevi is much lower in China than in other regions and people of other races. The pathology of large congenital melanocytic nevus may decide its "7B" distribution pattern.

\footnotetext{
Keywords: Chinese, retrospective cohort study, malignancy rate, 7B rule, distribution pattern, pathology, large congenital melanocytic nevus
}

\section{INTRODUCTION}

Large congenital melanocytic nevus (LCMN) is a rare disease that occurs in a range of $\sim 1$ in 20,000 to 1 in 500,000 newborns $(1,2)$. It is acknowledged that the most common somatic mutation in congenital melanocytic nevi (CMNs) is NRAS mutation, but there are potential alternative mechanisms. One recent research showed that NRAS mutation existed only in $57.1 \%$ of large/giant CMNs. The remains had gene fusions or point mutations involving other genes, such as BRAF (3). Once born with LCMN, the patients' appearance and life quality are significantly affected. Extensive research has demonstrated that LCMN conveys a high risk for melanoma formation. The largest meta-analysis of LCMN by Vourc'h-Jourdain et al. (4) reported an overall risk of malignancy of $\sim 2 \%$. Among Caucasian people with LCMNs, the lifetime risk of developing both cutaneous and non-cutaneous melanoma is $4.5-10 \%$ (5). Additionally, Price et al. (6) demonstrated that $\sim 5 \%$ of LCMNs transforms into melanoma, and half of these transformations occur early in life. 
By contrast, only around $2.3 \%$ of the general population will be diagnosed with melanoma of the skin during their lifetime, based on the data collected by the U.S. National Cancer Institute from 2015 to 2017.

The incidence rate of melanoma in Chinese patients with LCMNs remains unclear since only a few studies have investigated LCMNs and the risk of melanoma regarding Asian patients. A nationwide retrospective study performed in Korea found that melanoma developed in 3 of 131 LCMN patients, indicating the incidence rate was $2.29 \%$ (7). A systematic review showed that Southeast Asian patients with LCMNs, including 29 Chinese, 6 Malay, 1 Indian, and 3 Caucasian patients, did not develop any form of malignancy, with the longest follow-up extending to 38 years (8). Briefly, the above results all illustrate that the incidence of malignancy in Asians is significantly different from that in the Caucasian population (9).

Recently, Martins et al. (10) summarized and proposed a "6B" rule concerning the patterns of distribution of giant congenital melanocytic nevi (GCMNs), referring to the bolero, back, bathing trunk, breast/belly, body extremities, and body. However, the rule does not involve the region of head and face, where LCMNs also occur and create even more disease burden for these patients.

We supposed that the rate of malignancy and characteristics of LCMNs in China are different from those in other regions and people of other races. Therefore, a comprehensive study to analyze the characteristics, treatments, outcomes and risk of melanoma formation among Chinese LCMN patients is highly needed.

\section{METHODS}

\section{Patients}

The clinical and pathological data were collected from LCMN patients registered and treated at Shanghai Ninth People's Hospital, Shanghai Jiao Tong University School of Medicine from $1 / 1 / 1989$ to $8 / 31 / 2019$. A total of 1,171 patients with diverse nevus types were screened.

The inclusion criterion was that the size of CMN expected by adulthood, also known as the projected adult size (PAS), would be larger than $20 \mathrm{~cm}$ and smaller than $40 \mathrm{~cm}$ at its greatest diameter (11). For adults, the size of nevi was measured by physical examination whereas PAS graphs were used for children. This single-center database contained individuals' personal information, medical history and all reports from clinical tests.

This study was approved by the institutional ethical committee of Shanghai Ninth People's Hospital, Shanghai Jiao Tong University School of Medicine (SH9H-2019-T163-2, September 30, 2019). Informed consents were obtained from all individual participants included in the study.

\section{Clinical Information}

The details concerning clinical and phenotypes features of LCMNs were acquired through the electronic clinical database and telephone survey.

According to Krengel's recommendation, the morphological characteristics include color heterogeneity, surface rugosity, hypertrichosis, and the presence of dermal or subcutaneous nodules (11). There was a need to modify and adjust the standard to make the description more suitable for our research. Thus, we focused on whether the LCMN had the following features: evolving from the surface, dark in color, wrinkly and/or hairy surface, presenting nodules, hard of texture, painful to touch and/or itchy. Each phenotype was divided into the subgroup "Yes" or "No." The subgroups of nevi were decided through medical records and patients' answers. Regarding the anatomic localizations of LCMNs on the skin surface of patients, we used specific terms, including bonce (head and facial region), bolero, back, bathing trunk, breast/belly, body extremity and body to generalize the distribution patterns. Specifically, "Bonce" is referred to head and facial regions. "Bolero" is mainly on the upper back including the neck. "Back" is usually in round shape and does not involve buttocks or shoulders. "Bathing trunk" mainly involves the genital region and buttocks but excluding shoulders and neck. "Breast/belly" only distributes on chest or abdomen and no overlap with bolero or bathing trunk. "Body extremity" only locates on extremity and excludes of shoulders and genital region. "Body" is a pattern combines bolero and bathing trunk, which affects almost the entire body.

We also collected information about whether neurological symptoms, comorbidities, or relapses were present. Surgical excision procedures, such as skin graft, hemorrhoidectomy, flap graft and skin dermabrasion, and pathological diagnoses were also performed. Relapsed patients were carefully reviewed.

Additionally, typical histopathological characteristics were listed throughout the clinicopathological diagnosis reportsfor example, which tissue was hyperplasic or which layer had invaded melanocytes. The pathology of LCMN was classified as the junctional nevus, the intradermal nevus, the compound nevus, the blue nevus or the neuronevus. The junctional nevus, intradermal nevus and compound nevus were also collectively known as the melanocytic nevus.

\section{Statistical Analysis}

Descriptive statistics were presented using counts and percentages. Post-hoc tests following Fisher's exact test were used to determine which paired comparisons were significantly different if an association exists. The Benjamini-Hochberg procedure was used to correct $P$-values during the multiple comparison. Statistical analysis was performed using R 3.5.3, Statistical Software (Foundation for Statistical Computing, Vienna, Austria).

We hypothesized that phenotypes and distribution patterns of LCMNs among the melanocytic nevus, blue nevus and neuronevus groups were significantly different. The significance level was defined as a $P$-value of $<0.05$.

\section{RESULTS}

\section{Demographic and Clinical Characteristics of LCMNs}

One hundred thirty-three patients were diagnosed with LCMNs between $1 / 1 / 1989$ and $8 / 31 / 2019$ and included 58 (43.6\%) 
TABLE 1 | Baseline characteristics of large congenital melanocytic nevi.

\begin{tabular}{|c|c|}
\hline & No. (\%) \\
\hline Sample size & $133(100.0)$ \\
\hline Male & $58(43.6)$ \\
\hline Female & $75(56.4)$ \\
\hline \multicolumn{2}{|c|}{ Length of follow-up, Y } \\
\hline $0 \sim 1$ & $6(4.5)$ \\
\hline $1 \sim 2$ & $30(22.6)$ \\
\hline $2 \sim 3$ & $22(16.5)$ \\
\hline $3 \sim 4$ & 15 (11.3) \\
\hline $4 \sim 5$ & $14(10.5)$ \\
\hline $5 \sim 6$ & $10(7.5)$ \\
\hline $6 \sim 7$ & $10(7.5)$ \\
\hline $7 \sim 8$ & $8(6.0)$ \\
\hline 8〜9 & $6(4.5)$ \\
\hline $9 \sim 10$ & $3(2.3)$ \\
\hline$>10$ & $9(6.8)$ \\
\hline \multicolumn{2}{|l|}{ Distribution pattern } \\
\hline Bonce & $55(41.3)$ \\
\hline Bolero & $34(25.5)$ \\
\hline Back & $11(8.3)$ \\
\hline Bathing trunk & 15 (11.3) \\
\hline Breast/belly & $4(3.0)$ \\
\hline Body extremity & $9(6.8)$ \\
\hline Body & $5(3.8)$ \\
\hline \multicolumn{2}{|c|}{ Neurological symptom } \\
\hline Myasthenia gravis & $1(0.7)$ \\
\hline \multicolumn{2}{|l|}{ Surgical procedure } \\
\hline Skin graft & $52(39.1)$ \\
\hline Hemorrhoidectomy & $11(8.3)$ \\
\hline Flap graft & $64(48.1)$ \\
\hline Skin dermabrasion & $2(1.5)$ \\
\hline Surveillance & $4(3.0)$ \\
\hline \multicolumn{2}{|l|}{ Comorbid } \\
\hline Vitiligo & $1(0.7)$ \\
\hline Neurofibromatosis 1 & $1(0.7)$ \\
\hline
\end{tabular}

males and 75 (56.4\%) females. The median length of follow-up time was 43 months, and the longest follow-up time was 360 months. Specific statistics on the follow-up length are shown in Table 1.

Table 1 also shows that distributions of LCMNs in the 133 patients according to the new " $7 \mathrm{~B}$ " rule (Figure 1) modified from the " $6 \mathrm{~B}$ " rule. The new " $7 \mathrm{~B}$ rule" consists of 7 patterns: bonce (41.3\%), bolero (25.5\%), back (8.3\%), bathing trunk (11.3\%), breast/belly (3.0\%), body extremity (6.8\%), and body $(3.8 \%)$. Myasthenia gravis was present as a neurological symptom in one $(0.7 \%)$ patient. Comorbid diseases were also evaluated. Two patients had comorbid vitiligo $(0.7 \%)$ and neurofibromatosis type $1(0.7 \%)$. Skin graft (39.1\%), hemorrhoidectomy (8.3\%), flap graft $(48.1 \%)$ and skin dermabrasion (1.5\%) were performed for patients to remove nevi.

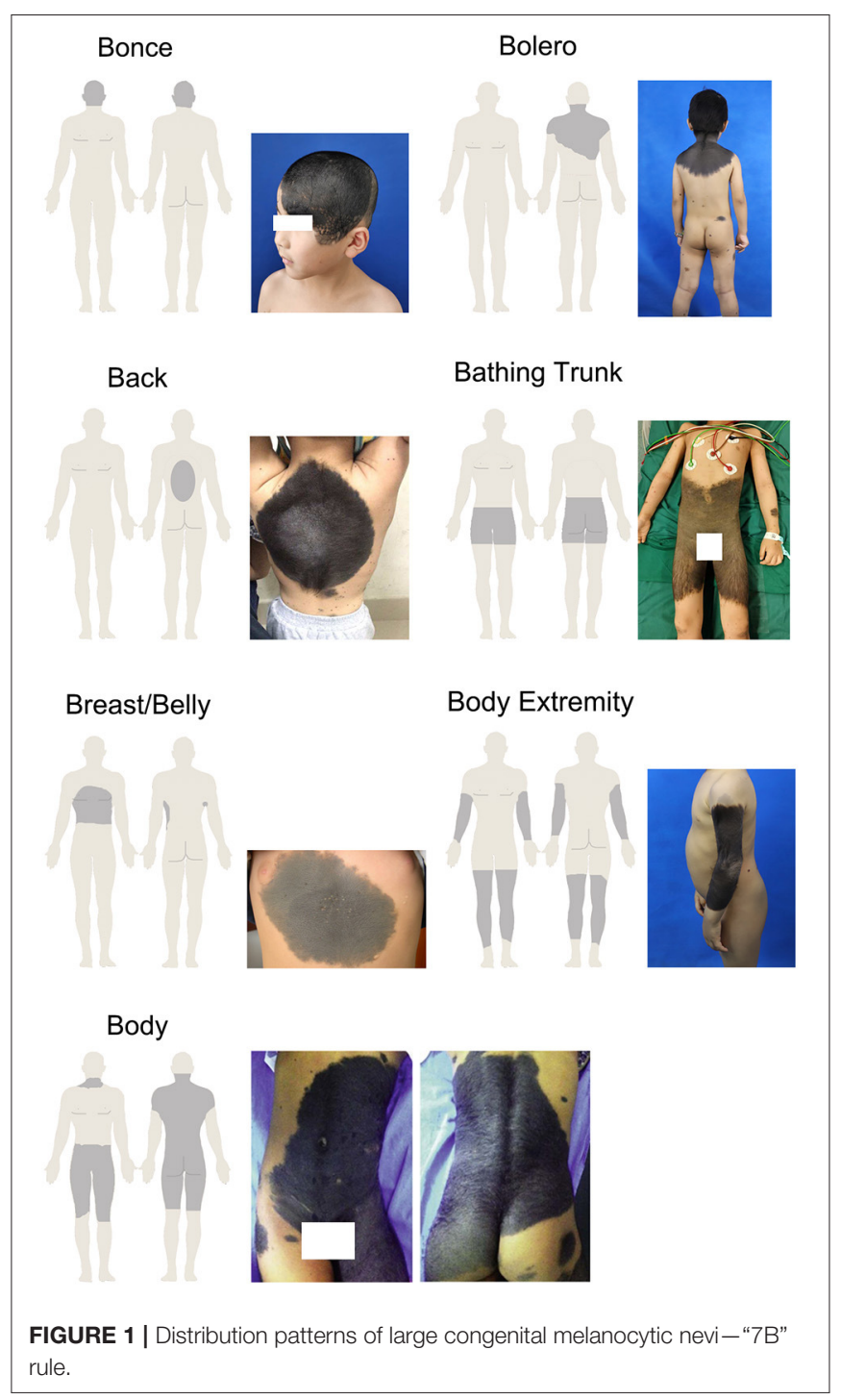

\section{Histopathological Findings of LCMNs}

Five pathological types were diagnosed among the 123 patients, and the pathological records of the rest of 10 (7.5\%) patients were missing. The categories of pathology were as follows: the junctional nevus $(2.3 \%)$, the intradermal nevus $(24.0 \%)$, the compound nevus (56.4\%), the blue nevus $(2.3 \%)$ and the neuronevus (7.5\%) (Figure 2). Only 93 of these 123 patients had a further detailed description of their histopathology; the remainder only had a confirmed diagnosis. We also have observed some typical histopathological features of LCMNs. One lesion may have multiple kinds of histopathological features simultaneously, such as collagenization and nodularization. Furthermore, 47 lesions had invaded to adipose tissue, and three lesions invade to striated muscle. These melanocytes infiltrated deeper and were harder to be removed by surgery.

Table 2 shows the eight phenotypes of LCMNs among the five main pathologies. Almost all LCMN cases were dark $(N=126$; $94.7 \%)$ and hairy $(N=127 ; 95.5 \%)$. Another common phenotype 

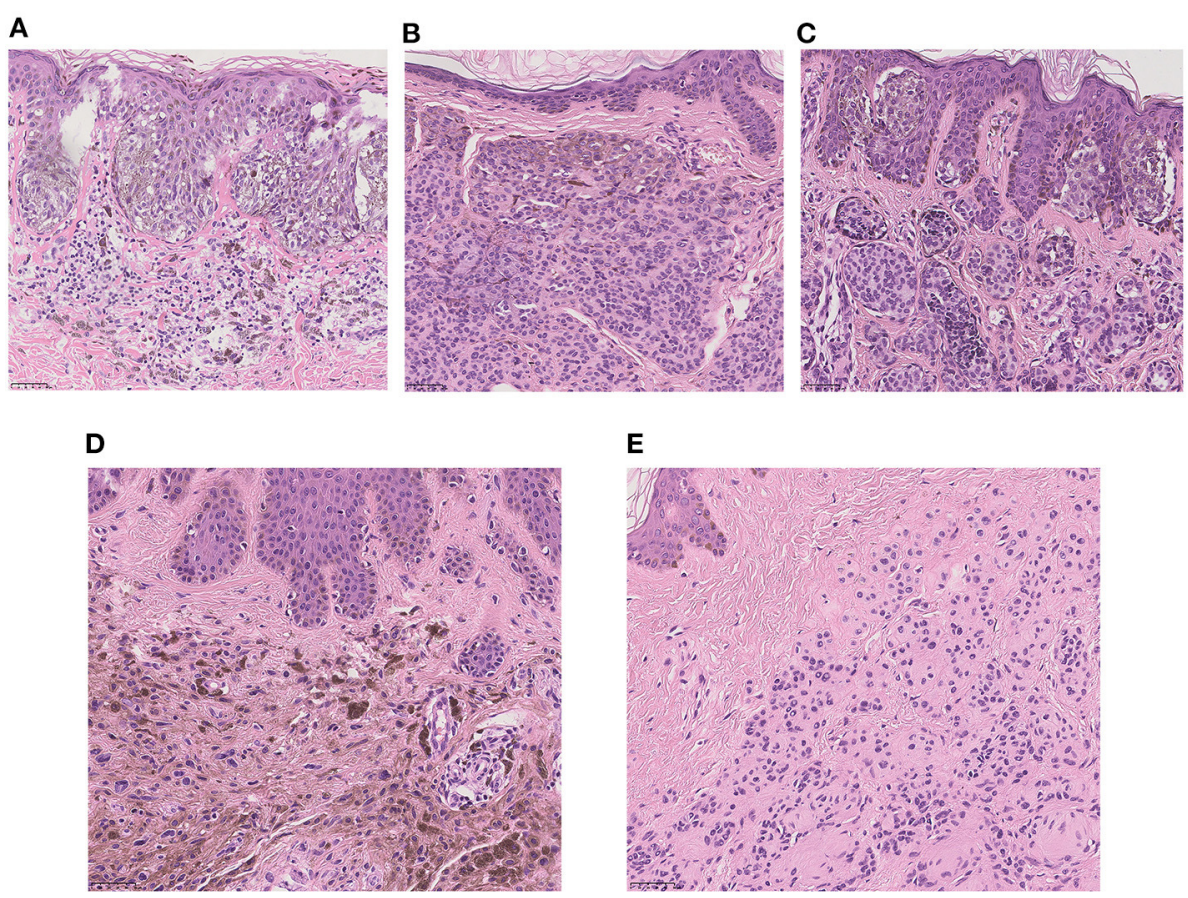

FIGURE 2 | High-power view of the typical histopathology of LCMNs (H\&E stain, $\times 20)$. (A) Junctional nevus. (B) Intradermal nevus. (C) Compound nevus. (D) Blue nevus. (E) Neuronevus.

TABLE 2 | Frequencies and percentage of different phenotypes of different pathological large congenital melanocytic nevi.

\begin{tabular}{|c|c|c|c|c|c|c|c|c|c|}
\hline & Evolving & Dark & Wrinkly & Hairy & Nodule & Hard & Painful & Itched & No. (\%) \\
\hline Junctional nevus & 2 & 3 & 3 & 3 & 1 & 0 & 0 & 1 & $3(2.3)$ \\
\hline Intradermal nevus & 19 & 31 & 23 & 31 & 17 & 6 & 1 & 3 & $32(24.0)$ \\
\hline Compound nevus & 49 & 71 & 58 & 70 & 42 & 13 & 0 & 11 & 75 (56.4) \\
\hline Blue nevus & 2 & 3 & 2 & 3 & 2 & 0 & 0 & 0 & $3(2.3)$ \\
\hline Neuronevus & 9 & 9 & 8 & 10 & 8 & 1 & 1 & 3 & $10(7.5)$ \\
\hline Unknown & 6 & 9 & 8 & 10 & 3 & 2 & 0 & 2 & $10(7.5)$ \\
\hline No. (\%) in total patients & $87(65.4)$ & $126(94.7)$ & $102(76.7)$ & $127(95.5)$ & $73(54.9)$ & $22(16.5)$ & $2(1.5)$ & $20(15.0)$ & $133(100.0)$ \\
\hline
\end{tabular}

was evolving, which was reported for $65.4 \%$ of all patients. Very few patients $(N=2 ; 1.5 \%)$ felt pain.

\section{Treatment Outcomes of LCMNs}

LCMNs relapse occurred in $3(2.3 \%)$ of the 133 people after surgery (Table 3 ), while the others remained stable. Notably, all of the relapsed patients had evolving, wrinkly, hairy LCMNs with nodules before surgery. However, each had undergone different operations for more than once. At the first stage, one had a skin graft, one had undergone hemorrhoidectomy, and one had a flap graft. The chance of relapse of each procedure equals the number of relapsed patients divided by the number of patients accepting this surgical procedure. We speculated that the chance of relapse of skin graft, hemorrhoidectomy and flap graft was 1.9, 9.0, and $1.6 \%$, respectively. The nevus cells of two patients had invaded the fat layer, but the detailed histopathology of another patient remained unknown due to data loss.

\section{Melanoma Formation in LCMN Patients and Systematic Review of Published Studies}

After such an extended follow-up, not a single case in our cohort developed melanoma. By contrast, foreign research over the latest 40 years has shown different results (Table 4). The range of the incidence rate of LCMNs developing into melanoma varied from 0 to $8.52 \%$. According to Hale, the rate was particularly high and reached $48.78 \%$ (20). However, 18 of the 22 studies were conducted only in western countries, and only a few included non-white people.

\section{Relationship Between Pathologies and "7B" of LCMNs}

By grouping the junctional nevus, intradermal nevus, and compound nevus together as the melanocytic nevus, we 
TABLE 3 | Clinical and pathological information about relapsed patients.

\begin{tabular}{ll}
\hline & No. (\%) \\
\hline Relapsed patients & $3(2.3)$ \\
Gender & \\
Male & $1(1.7)$ \\
Female & $2(2.6)$ \\
Distribution pattern & \\
Bonce & $1(1.8)$ \\
Bathing Trunk & $2(13.0)$ \\
Phenotype & \\
Evolving & $3(3.4)$ \\
Dark & $2(1.6)$ \\
Wrinkly & $3(2.9)$ \\
Hairy & $3(2.4)$ \\
Nodule & $3(4.1)$ \\
Hard & $1(4.5)$ \\
Painful & $0(0)$ \\
Itched & $1(5.0)$ \\
Surgical procedure & $1(1.9)$ \\
Skin graft & $1(9.0)$ \\
Hemorrhoidectomy & $1(1.6)$ \\
Intradermal nevus & $1(10.1)$ \\
Compound nevus & $1(1.3)$ \\
\hline Neuronevus & $1(10)$ \\
\hline
\end{tabular}

formed three populations-melanocytic nevus, blue nevus and neuronevus (Table 5). Statistical analysis using Fisher's exact test revealed a significant result $(P=0.0295 ; \alpha=0.05)$ of distribution patterns among three kinds of pathological types. Furthermore, the difference between " $7 \mathrm{~B}$ " distribution patterns of the melanocytic nevus and the neuronevus was significant ( $P=0.0249 ; \alpha=0.05)$. Thus, the melanocytic nevus and the neuronevus tend to occur in different distribution patterns on the body. In Figure 3A, the melanocytic nevus had the major proportion in every pattern except the "body," which consisted of $50 \%$ the melanocytic nevus and 50\% the neuronevus. Figure 3B shows us that all blue nevi in our cohort distributed as bonce, though there were only three cases in total.

\section{DISCUSSION}

Many types of CMNs have been identified. Among them, the LCMN is a rare and benign type of CMNs. LCMNs affect patients' appearance and self-esteem significantly. LCMNs have been defined in many ways and aspects. Zaal et al. (33) had performed a Medline literature search and summarized different clinical classifications of large/giant CMNs. Krengel et al. (11) proposed a new standard to define LCMNs (L1: $20-30 \mathrm{~cm}$; L2: $30-40 \mathrm{~cm}$ ). We adopted the new standard but did not distinguish L1 from L2 because of the unclear clinical records of some patients who registered in the system at early stages.
LCMNs can be located anywhere on the body and presented with various shapes. The descriptions of LCMN phenotypes are important because of their large sizes and wild heterogeneity. Some oncogenic mutations were only detected in a particular area of LCMNs, which indicates that different lesion areas may have different molecular characterization (3). Vanessa et al. proposed the " $6 \mathrm{~B}$ " rule to classify GCMNs in different locations into one certain pattern and suggested "bathing trunk" as the most frequently observed pattern (10). However, no specific description exists for patients with GCMNs on the head and/or facial regions in the " $6 \mathrm{~B}$ " rule. In our study, we created the " $7 \mathrm{~B}$ " rule based on the " $6 \mathrm{~B}$ " rule and discovered that the most frequent distribution of LCMNs was bonce. LCMNs that manifests in the region of the head and face have much worse effects on patients' appearances and lives. A recent study of quality of life (QoL) in children and adolescents with CMNs reflected that young patients experienced emotional impairment and felt shame if the CMNs were exposed to the public (34). We used Skindex-29, a widely acknowledged questionnaire for health-related quality of life (HRQoL) assessment, to evaluate the HRQoL of 19 patients in our cohort and obtain a consistent result. Reasonably, patients with congenital lesions on visible body parts, such as the face and hands, would visit the hospital and seek a cure more eagerly, explaining that bonce was most frequently observed in our cohort and caused admission rate bias.

Neurological symptoms rarely occurred in our patients, only one had myasthenia gravis. No correlation was found between LCMNs and myasthenia gravis, although a few nevi were observed that invaded striated muscle histopathologically in our study. Additionally, one case report mentioned that a 21-yearold male patient with myasthenia gravis had eruptive melanocytic nevi when treated with azathioprine and dexamethasone (35). In our study, two patients with LCMNs had concomitant vitiligo and neurofibromatosis 1 . Two patients also had vitiligo in a retrospective study in Korea (7). Some clinical evidence revealed the relevance of CMN in vitiligo or NF1. Van Geel et al. (36) concluded that $\mathrm{CMN}$ could affect the age of onset of vitiligo and trigger the development of halo nevi in patients with vitiligo. Another report presented a rare case of an association between LCMNs, halo nevus and vitiligo (37). Histological results presented both nevus cell nests and neural elements located in the dermis in some cases $(38,39)$, demonstrating that neurofibromatosis and large pigmented nevus have a common origin (40). In addition, a 21-year-old Korean girl with a large congenital nevocytic nevus had both neurotization and the onset of vitiligo (41). The above cases reflect a certain relationship between congenital nevus and vitiligo or NF1, which requires further study.

Usually, the histopathology of the nevus is classified according to the location and growth pattern of melanocytic cells. The junctional nevus comprises melanocytes located at the junction of the epidermis and dermis, the intradermal nevus comprises melanocytes limited in the dermis, and the compound nevus comprises the junctional nevus and the intradermal nevus. Currently, the blue nevus represents dermal arrest in the embryonal migration of neural crest melanocytes that fail to reach the epidermis, causing the pigment to appear deeper in the 
TABLE 4 | Studies of large congenital melanocytic nevi included in the systematic review.

\begin{tabular}{|c|c|c|c|c|}
\hline References, country & $\begin{array}{l}\text { No. of } \\
\text { LCMN } \\
\text { patients }\end{array}$ & Race or nationality & $\begin{array}{l}\text { No. of patients } \\
\text { developed MM }\end{array}$ & $\begin{array}{l}\text { Crude incidence of } \\
\text { MM in LCMNs }\end{array}$ \\
\hline Lorentzen et al. (12), Danmark & 151 & Danish & 3 & $1.99 \%$ (4.6\% lifetimes) \\
\hline Quaba and Wallace (13), UK & 39 & Caucasian & 2 & $\begin{array}{l}8.52 \% \text { (first } 15 \text { years } \\
\text { of life) }\end{array}$ \\
\hline Gari et al. (14), America & 54 & American & 1 & $1.85 \%$ \\
\hline $\begin{array}{l}\text { Ruiz-Maldonado et al. (15), } \\
\text { Mexico }\end{array}$ & 80 & Mexico & 4 & $5.00 \%$ \\
\hline Egan et al. (16), America & 46 & American & 2 & $4.35 \%$ \\
\hline Foster et al. (17), America & 46 & American & 0 & 0 \\
\hline Berg and Lindelöf (18), Sweden & 146 & Caucasian & 2 & Unknown \\
\hline Ka et al. (19), Sweden & 397 & Worldwide & 0 & 0 \\
\hline Hale et al. (20), America & 205 & American & 10 & $48.78 \%$ \\
\hline Bett $(21,22)$, America & 991 & $\begin{array}{l}1 \text { African, } 1 \text { Hispanic, } \\
1 \text { Japanese, others } \\
\text { were worldwide }\end{array}$ & 17 & $1.71 \%$ \\
\hline Zaal et al. (23), Netherland & 320 & Caucasian & 4 & $1.25 \%$ \\
\hline Yuin-Chew et al. (8), Singapore & 39 & $\begin{array}{l}29 \text { Chinese, } 6 \text { Malay, } 1 \\
\text { Indian, and } 3 \\
\text { Caucasian }\end{array}$ & 0 & 0 \\
\hline Vito et al. (24), Italy & 31 & Italian & 0 & 0 \\
\hline Warner et al. (25), America & 40 & American & 0 & 0 \\
\hline Fernandes et al. (26), Brazil & 5 & $\begin{array}{l}4 \text { white and } 1 \\
\text { non-white }\end{array}$ & 0 & 0 \\
\hline Kinsler et al. (27), UK & 50 & Caucasian & 0 & 0 \\
\hline Turkmen et al. (28), Turkey & 26 & Turku & 2 & $7.69 \%$ \\
\hline Chen et al. (29), Sydney & 31 & Australian & 0 & 0 \\
\hline Yun et al. (7), Korea & 131 & Yellow & 3 & $2.29 \%$ \\
\hline Kinsler et al. (30), UK & 448 & Caucasian & 10 & $2.23 \%$ \\
\hline Viana et al. (31), Brazil & 57 & South-American & 2 & $3.51 \%$ \\
\hline Fahradyan et al. (32), America & 14 & American & 0 & 0 \\
\hline
\end{tabular}

LCMN, large congenital melanocytic nevus; MM, melanocytic melanoma.

TABLE 5 | Pathology $\times$ distribution pattern cross tabulation.

\begin{tabular}{|c|c|c|c|c|c|c|c|c|c|}
\hline & \multirow[b]{2}{*}{ No. (\%) } & \multicolumn{7}{|c|}{ Distribution pattern } & \multirow[b]{2}{*}{ Total } \\
\hline & & Bonce & Bolero & Back & $\begin{array}{l}\text { Bathing } \\
\text { trunk }\end{array}$ & Breast/belly & $\begin{array}{c}\text { Body } \\
\text { extremity }\end{array}$ & Body & \\
\hline \multirow[t]{4}{*}{ Pathology } & Melanocytic nevus & $47(42.7)$ & $32(29.1)$ & $10(9.1)$ & $9(8.2)$ & $3(2.7)$ & $7(6.4)$ & $2(1.8)$ & $110(100.0)$ \\
\hline & Blue nevus & $3(100.0)$ & 0 & 0 & 0 & 0 & 0 & 0 & $3(100.0)$ \\
\hline & Neuronevus & $2(20.0)$ & $1(10.0)$ & $1(10.0)$ & $4(40.0)$ & 0 & 0 & $2(20.0)$ & $10(100.0)$ \\
\hline & Total & $52(42.3)$ & $33(26.8)$ & $11(8.9)$ & $13(10.6)$ & $3(2.4)$ & $7(5.7)$ & 4 (3.3) & $123(100.0)$ \\
\hline
\end{tabular}

skin than in ordinary nevi. Melanocytes of the neuronevus is also located intradermally and have typical nerve-like growth pattern. In our study, most LCMN cases were melanocytic nevi, and $68.1 \%$ of them were compound nevi. The blue nevus occurred the least frequently. The result was reasonable because conventional melanocytic nevus is the most common nevus pathological type, and the blue nevus is not commonly acquired, with a $3-5 \%$ prevalence in adults in the United States (42).
The histopathological features of LCMNs were not isolated but overlapped. Additionally, LCMNs invade into adipose or striated muscle tissue, indicating that LCMNs have great heterogeneity and diversity.

Only three patients relapsed. We assumed the current relapsed nevi were derived from original lesions because all relapsed LCMNs had invaded the fat layer. Thus, some melanocytes might have infiltrated too deeply to be removed entirely by surgery. 
A

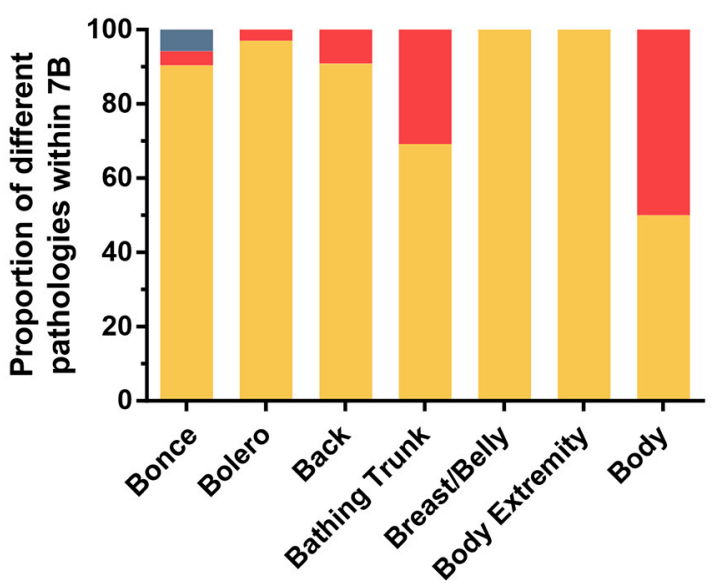

B

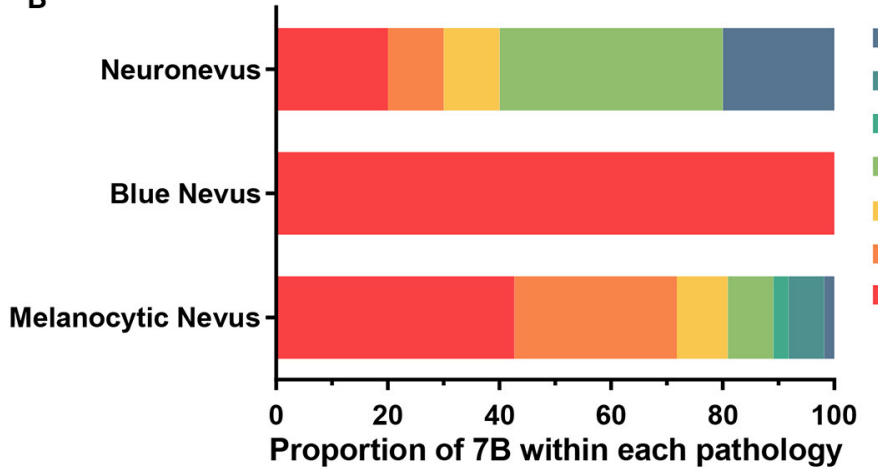

Neuronevus

Blue Nevus

Melanocytic Nevus

FIGURE 3 | (A) Showing the proportion of three pathological types of LCMNs in each distribution pattern according to the "7B" rule. (B) Showing the proportion of each distribution pattern classified by the "7B" rule in different pathological types of LCMNs.

With approximately the same number of patients as the Korean cohort, we found no malignant cases while there were 3 in them. On the one hand, our data were only collected from a single center, yet researchers pooled data from 40 university hospitals in Korea, representing a much more comprehensive range of cases than ours. On the other hand, this result implies that the risk of LCMNs becoming melanoma differs greatly from region to region as well as from race to race. Although the molecular mechanisms of the formation and development of LCMNs still remain unclear, they should be taken into consideration. Races, food, climates and all the environment around patients can potentially influence the gene expression and cause mutations in LCMNs. The result reminds us the mechanisms behind this disease could be complicated and related to multiple factors. It also suggests that the risk of LCMNs transforming into melanoma is extremely low among Chinese people. Thus, it would be inaccurate if we directly use the estimated risk in other races to predict malignancy in Chinese or Asian people.

Krengel et al. (10) summarized the characteristics of each CMN size category and marked the phenotypes as three degrees from " 0 " to " 2 ." Although standard markers defined the degree, it is still confusing and almost impossible for our patients to describe their nevus type precisely through phone calls. To solve this problem, we extended and adjusted the content of the study by adding four additional phenotypes of lesions but simplified subgroup to: "yes" or "no." This standard led to a much easier and faster evaluation of LCMNs.

To our best knowledge, our study is the first to investigate the relevance between pathologies and distribution patterns of nevi. According to pathological classification, the junctional nevus, intradermal nevus and compound nevus are considered the melanocytic nevus. The significant result among the melanocytic nevus, blue nevus and neuronevus, as well as the significant result between the melanocytic nevus and neuronevus, proved that the pathology of the LCMN is correlated with its pattern of distribution. The pathology and distribution correlation was not clarified mainly due to the inadequate statistical sample size. After collecting and analyzing a sufficient number of cases, we hope to figure out whether its pathology decides the distribution pattern of the LCMN. If so, we can infer the pathological type of the LCMN through its pattern before acquiring the exact pathological diagnosis by invasive biopsy. 
In conclusion, 133 Chinese patients with LCMNs were carefully analyzed and some meaningful results were obtained. We proposed a brand-new term, "?once," for the "7B" rule to describe distributions of LCMNs more comprehensively. Moreover, the specific distribution pattern may imply a potential pathology of the LCMN. Most importantly, we demonstrated the remarkably low incidence of melanoma arising from LCMNs in China, indicating the low risk of malignancy. We are also aware that the rate of malignancy in these patients may still be higher than that in the general population and further studies would be required to validate this conclusion. Additionally, treatments should be re-evaluated and the necessity of surgery should be reconsidered.

Although the present study is the largest and longest retrospective LCMN cohort in Asia, filling a huge gap in this field, there are still limitations. Firstly, this was a single-center analysis, which could miss multiple eligible patients across China. Secondly, many medical records by handwriting were unavailable until the electronic clinical database was created, causing a significant loss which could affect the study's accuracy. Although the follow-up time in our research is longer than many other retrospective cohort studies and the longest follow-up time is 360 months, $65.4 \%$ of patients in our cohort were followed up within 5 years and the median length of follow-up time was 43 months. The development of melanoma may require more time. We are supposed to follow up with these patients continually and expand our cohort to find out if there will be different results. Last but not least, the lack of magnetic resonance imaging (MRI) examination for each patient's lesion made us unable to see the direct structure of LCMN, which was also important.

We hope our findings not only help clinical doctors assess patient's condition and guide the treatment plan for the disease, but provide useful information and new ideas to inspire researchers for future investigations.

\section{DATA AVAILABILITY STATEMENT}

The raw data supporting the conclusions of this article will be made available by the authors, without undue reservation.

\section{REFERENCES}

1. Castilla EE, da Graça Dutra M, Orioli-Parreiras IM. Epidemiology of congenital pigmented naevi: I. Incidence rates and relative frequencies. $\mathrm{Br}$. J. Dermatol. (1981) 104:307-15. doi: 10.1111/j.1365-2133.1981.tb00954.x

2. Rhodes AR. Melanocytic precursors of cutaneous melanoma. Estimated risks and guidelines for management. Med. Clin. North Am. (1986) 70:3-37. doi: 10.1016/S0025-7125 (16)30966-X

3. Martins da Silva V, Martinez-Barrios E, Tell-Martí G, Dabad M, Carrera C, Aguilera P, et al. Genetic abnormalities in large to giant congenital nevi: beyond NRAS mutations. J. Invest. Dermatol. (2019) 139:9008. doi: 10.1016/j.jid.2018.07.045

4. Vourc'h-Jourdain M, Martin L, Barbarot S. Large congenital melanocytic nevi: therapeutic management and melanoma risk: a systematic review. J. Am. Acad. Dermatol. (2013) 68:493-8.e1-14. doi: 10.1016/j.jaad.2012.09.039

\section{ETHICS STATEMENT}

The studies involving human participants were reviewed and approved by Shanghai Ninth People's Hospital, Shanghai Jiao Tong University School of Medicine. Written informed consent to participate in this study was provided by the participants' legal guardian/next of kin. Written informed consent was obtained from the minor (s)' legal guardian/next of kin for the publication of any potentially identifiable images or data included in this article.

\section{AUTHOR CONTRIBUTIONS}

QL and ZW contributed to the conception and design of the work. HW, WW, JL, and YG collected clinical information. HW and JL wrote the manuscript. JL performed data analysis. $\mathrm{WW}$ and YG contributed remarkably to interpretation of data. $\mathrm{XC}, \mathrm{CW}, \mathrm{JR}$, and BG helped with constructive discussions. All authors substantively revised the work and have approved the submitted version.

\section{FUNDING}

This work was supported by grants from Youth Doctor Collaborative Innovation Team Project (QC201803) of Shanghai Ninth People's Hospital, Shanghai Jiaotong University School of Medicine; the Project of Biobank (No. YBKA201901) from Shanghai Ninth People's Hospital, Shanghai Jiao Tong University School of Medicine; the Shanghai Youth Top-Notch Talent Program (201809004); Chenguang Program supported by Shanghai Education Development Foundation and Shanghai Municipal Education Commission (19CG18) and Science and Technology Commission of Shanghai Municipality (19JC1413) and Shanghai Rising-Star Program (20QA1405600).

\section{SUPPLEMENTARY MATERIAL}

The Supplementary Material for this article can be found online at: https://www.frontiersin.org/articles/10.3389/fmed. 2021.637857/full\#supplementary-material

5. Lyon VB. Congenital melanocytic nevi. Pediatr. Clin. North Am. (2010) 57:1155-76. doi: 10.1016/j.pcl.2010.07.005

6. Price HN, Schaffer JV. Congenital melanocytic nevi-when to worry and how to treat: facts and controversies. Clin. Dermatol. (2010) 28:293302. doi: 10.1016/j.clindermatol.2010.04.004

7. Yun SJ, Kwon OS, Han JH, Kweon SS, Lee MW, Lee DY, et al. Clinical characteristics and risk of melanoma development from giant congenital melanocytic naevi in Korea: a nationwide retrospective study. Br. J. Dermatol. (2012) 166:115-23. doi: 10.1111/j.1365-2133.2011.10636.x

8. Chan Y-C, Giam Y-C. A retrospective cohort study of Southeast Asian patients with large congenital melanocytic nevi and the risk of melanoma development. J. Am. Acad. Dermatol. (2006) 54:778-82. doi: 10.1016/j.jaad.2006.02.063

9. Lovett A, Maari C, Decarie J-C, Marcoux D, McCuaig C, Hatami A, et al. Large congenital melanocytic nevi and neurocutaneous melanocytosis: 
one pediatric center's experience. J. Am. Acad. Dermatol. (2009) 61:76674. doi: 10.1016/j.jaad.2008.11.022

10. Martins da Silva VP, Marghoob A, Pigem R, Carrera C, Aguilera P, PuigButillé JA, et al. Patterns of distribution of giant congenital melanocytic nevi (GCMN): the 6B rule. J. Am. Acad. Dermatol. (2017) 76:68994. doi: 10.1016/j.jaad.2016.05.042

11. Krengel S, Scope A, Dusza SW, Vonthein R, Marghoob AA. New recommendations for the categorization of cutaneous features of congenital melanocytic nevi. J. Am. Acad. Dermatol. (2013) 68:441-51. doi: 10.1016/j.jaad.2012.05.043

12. Lorentzen M, Pers M, Bretteville-Jensen G. The incidence of malignant transformation in giant pigmented nevi. Scand. J. Plast. Reconstr. Surg. (1977) 11:163-7. doi: 10.3109/02844317709025513

13. Quaba AA, Wallace AF. The incidence of malignant melanoma (0 to 15 years of age) arising in "large" congenital nevocellular nevi. Plast. Reconstr. Surg. (1986) 78:174-81. doi: 10.1097/00006534-198608000-00004

14. Gari LM, Rivers JK, Kopf AW. Melanomas arising in large congenital nevocytic nevi: a prospective study. Pediatr. Dermatol. (1988) 5:1518. doi: 10.1111/j.1525-1470.1988.tb01161.x

15. Ruiz-Maldonado R, Tamayo L, Laterza AM, Durán C. Giant pigmented nevi: clinical, histopathologic, and therapeutic considerations. J. Pediatr. (1992) 120:906-11. doi: 10.1016/S0022-3476 (05)81958-4

16. Egan CL, Oliveria SA, Elenitsas R, Hanson J, Halpern AC. Cutaneous melanoma risk and phenotypic changes in large congenital nevi: a followup study of 46 patients. J. Am. Acad. Dermatol. (1998) 39:923-32. doi: 10.1016/S0190-9622(98)70264-6

17. Foster RD, Williams ML, Barkovich AJ, Hoffman WY, Mathes SJ, Frieden IJ. Giant congenital melanocytic nevi: the significance of neurocutaneous melanosis in neurologically asymptomatic children. Plast. Reconstr. Surg. (2001) 107:933-41. doi: 10.1097/00006534-200104010-00005

18. Berg P, Lindelöf B. Congenital melanocytic naevi and cutaneous melanoma. Melanoma Res. (2003) 13:441-5. doi: 10.1097/00008390-200310000-00002

19. Ka VSK, Dusza SW, Halpern AC, Marghoob AA. The association between large congenital melanocytic naevi and cutaneous melanoma: preliminary findings from an Internet-based registry of 379 patients. Melanoma Res. (2005) 15:61-7. doi: 10.1097/00008390-200502000-00010

20. Hale EK, Stein J, Ben-Porat L, Panageas KS, Eichenbaum MS, Marghoob AA, et al. Association of melanoma and neurocutaneous melanocytosis with large congenital melanocytic naevi-results from the NYU-LCMN registry. $\mathrm{Br}$. J. Dermatol. (2005) 152:512-7. doi: 10.1111/j.1365-2133.2005.06316.x

21. Bett BJ. Large or multiple congenital melanocytic nevi: occurrence of cutaneous melanoma in 1008 persons. J. Am. Acad. Dermatol. (2005) 52:7937. doi: 10.1016/j.jaad.2005.02.024

22. Bett BJ. Large or multiple congenital melanocytic nevi: occurrence of neurocutaneous melanocytosis in 1008 persons. J. Am. Acad. Dermatol. (2006) 54:767-77. doi: 10.1016/j.jaad.2005.10.040

23. Zaal LH, Mooi WJ, Klip H, van der Horst CM. Risk of malignant transformation of congenital melanocytic nevi: a retrospective nationwide study from The Netherlands. Plast. Reconstr. Surg. (2005) 116:19029. doi: 10.1097/01.prs.0000189205.85968.12

24. Ingordo V, Gentile C, Iannazzone SS, Cusano F, Naldi L. Congenital melanocytic nevus: an epidemiologic study in Italy. Dermatology. (2007) 214:227-30. doi: 10.1159/000099587

25. Warner PM, Yakuboff KP, Kagan RJ, Boyce S, Warden GD. An 18-year experience in the management of congenital nevomelanocytic nevi. Ann. Plast. Surg. (2008) 60:283-7. doi: 10.1097/SAP.0b013e318095a784

26. Fernandes NC, Machado JLR. Clinical study of the congenital melanocytic naevi in the child and adolescent. An. Bras. Dermatol. (2009) 84:12935. doi: 10.1590/S0365-05962009000200005

27. Kinsler VA, Birley J, Atherton DJ. Great ormond street hospital for children registry for congenital melanocytic naevi: prospective study 1988-2007. Part 1-epidemiology, phenotype and outcomes. Br. J. Dermatol. (2009) 160:14350. doi: $10.1111 /$ j.1365-2133.2008.08849.x
28. Turkmen A, Isik D, Bekerecioglu M. Comparison of classification systems for congenital melanocytic nevi. Dermatol. Surg. (2010) 36:1554-62. doi: 10.1111/j.1524-4725.2010.01641.x

29. Chen AC-C, McRae MY, Wargon O. Clinical characteristics and risks of large congenital melanocytic naevi: a review of 31 patients at the Sydney children's hospital. Aust. J. Dermatol. (2012) 53:219-23. doi: 10.1111/j.1440-0960.2012.00897.x

30. Kinsler VA, O'Hare P, Bulstrode N, Calonje JE, Chong WK, Hargrave D, et al. Melanoma in congenital melanocytic naevi. Br. J. Dermatol. (2017) 176:1131-43. doi: 10.1111/bjd.15301

31. Viana ACL, Goulart EMA, Gontijo B, Bittencourt FV. A prospective study of patients with large congenital melanocytic nevi and the risk of melanoma. An. Bras. Dermatol. (2017) 92:200-5. doi: 10.1590/abd1806-4841.20175176

32. Fahradyan A, Wolfswinkel EM, Tsuha M, Reinisch JF, Magee W, III, Hammoudeh JA, et al. Cosmetically challenging congenital melanocytic nevi. Ann. Plast. Surg. (2019) 82 (5S Suppl. 4):S306-S9. doi: 10.1097/SAP.0000000000001766

33. Zaal LH, Mooi WJ, Sillevis Smitt JH, van der Horst CMAM. Classification of congenital melanocytic naevi and malignant transformation: a review of the literature. Br. J. Plast. Surg. (2004) 57:707-19. doi: 10.1016/j.bjps.2004.04.022

34. Neuhaus K, Landolt MA, Theiler M, Schiestl C, Masnari O. Skin-related quality of life in children and adolescents with congenital melanocytic nevi - analysis of self- and parent reports. J. Eur. Acad. Dermatol. Venereol. (2020) 34:1105-11. doi: $10.1111 /$ jdv.16131

35. Braun SA, Helbig D, Frank J, Hanneken S. Eruptive melanocytic nevi during azathioprine therapy in myasthenia gravis. Hautarzt. (2012) 63:7569. doi: $10.1007 / \mathrm{s} 00105-012-2440-\mathrm{x}$

36. van Geel N, Van Poucke L, Van de Maele B, Speeckaert R. Relevance of congenital melanocytic naevi in vitiligo. Br. J. Dermatol. (2015) 172:10527. doi: $10.1111 /$ bjd. 13444

37. Silveira MLd, Ferreira FR, Alvarenga ML, Mandelbaum SH. Association of giant congenital melanocytic nevus, halo nevus and vitiligo in a 75-year-old patient. An. Bras. Dermatol. (2012) 87:288-91. doi: 10.1590/S0365-05962012000200015

38. Bousema MT, Vuzevski VD, Oranje AP, Heule F, Stolz E, van Joost T. Non-von Recklinghausen's neurofibromatosis resembling a giant pigmented nevus. J. Am. Acad. Dermatol. (1989) 20 (2 Pt 2):358-62. doi: 10.1016/S0190-9622(89)70046-3

39. Zvulunov A, Metzker A. Neurofibromatosis versus giant pigmented nevus. J. Am. Acad. Dermatol. (1990) 23 (5 Pt 1):956-7. doi: 10.1016/S0190-9622(08)80723-2

40. Silfen R, Skoll PJ, Hudson DA. Congenital giant hairy nevi and neurofibromatosis: the significance of their common origin. Plast. Reconstr. Surg. (2002) 110:1364-5. doi: 10.1097/00006534-20021000000032

41. Shin JH, Kim MJ, Cho S, Whang KK, Hahm JH. A case of giant congenital nevocytic nevus with neurotization and onset of vitiligo. J. Eur. Acad. Dermatol. Venereol. (2002) 16:384-6. doi: 10.1046/j.1468-3083.2002.00563.x

42. Roth RR, Acker SM. Blue Nevi. (2018). Medscape. Available online at: https://emedicine.medscape.com/article/1056397-overview\#a6 (accessed October 30, 2020).

Conflict of Interest: The authors declare that the research was conducted in the absence of any commercial or financial relationships that could be construed as a potential conflict of interest.

Copyright (c) 2021 Wang, Wang, Lu, Gu, Cui, Wei, Ren, Gu, Wang and Li. This is an open-access article distributed under the terms of the Creative Commons Attribution License (CC BY). The use, distribution or reproduction in other forums is permitted, provided the original author(s) and the copyright owner(s) are credited and that the original publication in this journal is cited, in accordance with accepted academic practice. No use, distribution or reproduction is permitted which does not comply with these terms. 